\title{
To optimize the safety guarantee mechanism of the rural self-produced food
}

\author{
Lu Yanling \\ Department of management \\ China West Normal University \\ Nanchong, China \\ 493859764@qq.com
}

\author{
Liu Yi \\ Vocational and Technical College \\ China West Normal University \\ Nanchong, China \\ cleverbag@qq.com
}

\begin{abstract}
Rural self-produced food is the food that farmers produce and sell in the rural market. We found some problems by observing the actual condition of rural food security and reading relevant literature. The lack of security assurance for production, circulation, sales and consumption; the relevant laws and regulations lack rigid constraints and objectives; the government lacks strict management and control system. In order to ensure the safety of the rural villagers and the stability of the countryside, the article puts forward some suggestions: 1 . Perfecting the legal system of rural food safety; 2. Fulfilling government' supervising responsibilities for rural food safety; 3 . Cultivating the food safety consciousness of the farmers; 4 . Establishing the protection network of rural food safety.
\end{abstract}

Key words-countryside; Self-produced food; Security; Construction of Mechanism

\section{I . INTRODUCTION}

On the CPC Agricultural Meeting of 2013, Mr. Xi Jinping proposed that whether we can satisfy our civilian on food safety or not is a vital test of our governing ability. Some people will doubt our administration ability if we can't meet food safety or even fail to meet that in long terms. So we must pay high attention and try our best to achieve it. Food is the paramount necessity of the people, the food must be sure safety, and food safety is the basic guarantee of civilian life.

According to National health ministry statistics, there was 160 food poisoning incidents happened on 2014, result to 5657 people was poisoned, 110 people died. Compared with 2013 on statistic, food poisoning incident, the number of poisoning and death toll respectively increased 5.3\%, 1.8\%, and $0.9 \%$. Although so much measurement was took by party and government, but food safety issue still facing a urgent and difficult situation. Especial in countryside, since the traditional small-scale peasant transformed to socialization small scale peasant, the self-autonomy of small-scale peasant produce and live make them more close to market, currently small-peasant self-producing and sale food have become an important tool for countryside development. But along with the expanding of rural self-produce and sales market, the rural food safety hindered to build rural harmonious society. From the rich rural food study, there are different views on defining and studying rural food. Such as Shun Yanhua, Ying Ruiyao research rural food safety based on the point of rural fake food, Liao Tianhu was studying rural food safety without a clear definition on rural food safety, so the content more like this kind food which circulating in all rural area. Wang Bei investigated rural self-produce, semi-produce and foreign food in his study. Ju Ronghui, Wang Xiaomei main study rural food safety on the basis of food which was brought in rural from city, Zhou Guangyue study from semi-produced food and the food come from outside etc. Most of research and definition for rural food are obscure, less case to analyze rural food safety only based on rural self-produced food, and to solve this problem from peasant themselves.

\section{П.PRESENT PROBLEMS}

The main expression that rural self-produced food lack of safety guarantee

\section{A. The food production lack of safety standards}

The current rural is the socialized rural, they are no longer like the traditional society for the purpose of survival, 
but for the purpose of monetary income maximization. Therefore, they produce food according to the principle of minimizing cost, they lack of the necessary equipment and capital investment in environment of food production, safety test, selection of raw materials, food quality is not guaranteed. Especially the little food workshops in countryside, according to a large number of rural cadre reported, the food was produced by rural the little food workshops especially popular among rural children, due to the child's parents are working outside to earn money, grandpa and grandmother-in-law doting them, and allowing them to buy the food, so these unhealthy food seriously harm to the health and the life safety of children. In the rural with strong "acquaintances" plot relatively, it provides a hotbed for little food workshop as the villagers lack of right-protection awareness.

B. The food circulation and sales link lack of safety supervision

A lot of rural self-produced food is circulated and selling in the local, due to the low level of farmers' consumption, so the low price of food in rural areas has broad market. Rural self-produced food costs are lower relative to other food, more accepted in the rural areas, so more widely circulated in the local. However, the circulation link of those food is chaos in rural, the lack of safety regulation. Only pay attention to price and ignore the quality when purchased food, so, even "three non-food products" have a clear road in rural. And most managers lack of the necessary testing facilities and safety knowledge, they measure the food whether is safety by the standards of "would die or not". And the characteristics of "wide area and scattered", it will be difficult to ensure the food hygiene and food quality meet the requirements of national. At the same time, these rural points of sale are good at dealing with the inspection of local government. They would hide unqualified food when government temporarily inspect, and they would go on sell after the Inspection team gone, this was called "guerrilla warfare".

\section{Food consumption link lack of security}

According to the ministry of commerce issued the circulation of 2005 food safety survey, rural consumers in China, though $74.4 \%$ of consumers will consider appropriate food safety issues, but $43.7 \%$ of consumers are still the cheaper price as the first choice for buying food. In the countryside, not only independent producers or marketers with "eating will die or not" standard to judge the quality of the food, but also the vast number of consumers will first consider the price selected in price and quality, the low price to become the first choice for most rural consumers. Under the action of law of value of "demand has the market", the villagers limited purchasing power formed consumption habits of "eating will die or not", so the rural judgment standard of "eating will die or not" let a part of fake food of the rural autonomous production widespread.

\section{III.ANALYSIS OF CAUSES}

The main factors of restriction of rural autonomous production food security

\section{A. The imperfection of rural food safety law system}

The Food Safety Law of the People's Republic of China (hereinafter referred to as the Food Safety Law) for its process of implementation, it has the characteristics of clear policy method. Because of the complexity of the food industry and its poor operability, lead to the enforceability of administrative law enforcement and justice poor, resulting in the food safety problems emerge in endlessly. For example: "food production or marketing", in the fourth chapter of Food Safety Law, mainly provides direction requirements in the process of food production and operation, but there is no clear indicators to specific food production standards, also no the legal responsibility of violation of regulations. The content of the Food Safety Law is relatively fragmented, and it does not integrate into the other system. In addition, the third chapter of Food Safety Law "food safety standards", specific standard has no clear data as judgment, resulting in the law enforcement selected artificially.

The complexity of rural autonomous food production has become a key issue for the food industry. Food Safety Law has no special provision of legal content aimed at special rural field, only slightly involves factors such as pesticides, environmental health. Combined with the unique rural production, consumption habit, make rural food security law enforcers fractious, struggling in the specific law enforcement process.

B. Rural food safety supervision system lags behind the 
need of social development

At present, the development of rural economy lead to the changes in the countryside, and formed the complicated social features. The food industry also stimulated a large number of farmers of left-behind in rural land, farmers' self-product, and sales food is one of the symbols that rural social economic development. On the positive sense, it is convenient for the needs of the farmers' life, and it gets rid of the situation that too much dependence on outside food import However, it also brings more complex social problems. In particular, the original rural food safety regulator can't adapt to the current complex social demands. In allusion to change that the current rural autonomous production and sales of food adjustment measures were not taken, lead to the absence of rural food safety regulatory system. Performance at the insufficient ability of guide that the local government for rural food regulatory, rural food independent production, flow, sales and consumption each link lack of scientific monitoring mechanism. The problems such as fake, shoddy, falsification, shoddy, abuse of food additives occur frequently in the rural autonomous production and operation of food. The supervision on rural food safety is not enough, lack of professional talents and strict punishment system.

\section{The villagers own food safety consciousness is weak}

According to the food poisoning incidents in rural, the fundamental reason is that the villagers' food safety consciousness is weak. The villagers does not pay attention to food hygiene when product, sales and eat. In the process of production, the villagers have some contaminated food behavior such as Ingredients cleaning not net, improper placement. Villagers decide to buy food rely on trust and price in rural "acquaintance society". Even have question after eating it, as long as there is no significant poisoning, most of the villagers recognize unlucky, few will use legal weapons to be investigated for responsibility. Of course there is also a helpless situation, even if the villagers want to complain, but don't know who they should complain to, how to complain, because of extremely lacking right-protection awareness forced they only content with the status of now. This makes the rural self-produced food market developing and expanding in the villages and towns.

\section{IV.CONCLUSION AND COUNTERMEASURES}

Construction of the guarantee mechanism of rural self-produced food safety

\section{A. Perfecting the legal system of rural food safety}

At present, our country's food safety law is the legal system of multi-level and departmental, require multiple departments cooperate with each other to smooth implementation. After enacted the Food Safety Law, our country has already formed the law system of food safety protection that take Food Safety Law as the main guide, and take those as the main body that the Product Quality Law of the People's Republic of China, the Standardization Law of the People's Republic of China, the Law of the People's Republic of China on Agricultural Product Quality Safety, and take those as the guarantee that the Law of the PRC on the Protection of the Rights and Interests of Consumers, the Criminal Law of the People's Republic of China and so on. But the Food Safety Law needs to perfect. First, refine the legal provisions, clear its detailed institution and standards on the basis of the guiding, making its have more scientific and reasonable operation. Second, consolidate the contents of the relevant laws and regulations, and rendered in the law, formed a complete system. Clear institution of punishment, according to the different levels of illegal behavior, enact strict punishment standard. Third, the Legal content requires corresponding adjustment and update according to the social development, especially for the special field of rural, according to special requirements, adding a special chapter in the law to solve the problem of rural food safety, and give clear specification to rural self-production and sales food.

B. Fulfilling government' supervising responsibilities for rural food safety

Perfect supervision system of food safety is the guarantee of rural food safety, only the local government and the villagers' participation, to build a sound rural food safety supervision system. First, the government should clear its own role, strictly implement the supervision responsibilities. On the supervision measures, the local government can make local actual condition combination with the Food Safety Law of the People's Republic of China, to formulate the rules and regulations of local food safety, increase the comprehensive 
governance's effort of national laws and local regulations. At the same time, local government actively set up the "commission of rural food safety ", responsible for each country's food safety, to ensure "where have food, there have supervision". In terms of resources, take measures to strengthen in many ways, ensure enough human resources, material resources and financial resources, to provide necessary and enough basic protection for supervision; In terms of publicity, actively encourage social masses to participate in the rural food supervision system, increasing the propaganda of food safety knowledge. At the same time, strictly comply with national laws and local rules and regulations when the supervision departments manage food safety, strictly control the expansion of rural food market, perfecting the supervision and management methods, and strengthen the supervision to rural food market.

C. Cultivating the food safety consciousness of the farmers

Consumers are the carriers of rural food safety. Villagers' food safety awareness is the key to solve the problem of rural food safety. The rural self-produced food of producers and consumers are local villagers, so the villagers' food safety awareness not only related to the safety of others, but also closely involved with him own safety. According to the broad masses of farmers who cultural level are low, we can choose specific video, images, and other popular social activity, popularized the knowledge of food safety. making them standard production process, and Strengthen the consciousness of environmental health when self-product and sales food, changing the idea that profit is the highest, to establish the good faith relationship between production and sales of food. Gradually Change the villagers' value orientation when they buying the rural self-produced food, by the "price priority" turn into the view that quality is the same as price, make people consciously buy safe, harmless food. At the same time enhance the capacity of villagers to protect themselves, give full play the function of social supervision, while in rural areas is an acquaintance society, but to encourage villagers adhere to the attitude of "ruthless face under the harmful food", consciously expose, resist the various rural shoddy food, and make it have no market.

\section{Establishing the protection network of rural food safety}

With the expansion of the rural self-produced food market, to improve the severe situation faced by the rural food safety, the power of the government alone is not enough, must also be leveraged social forces, mobilize the public participation, form the three-dimensional rural food safety protection network. In terms of policy making, more widely to solicit public opinion, listen to public opinion, absorb the intelligence, maintain the interests of the people; Intensify information disclosure, and publish the chance of work in time, maintaining people's right to know, to participate, supervise. Rural residents may establish consumer cooperative, this can partially solve the problem of rural self-produced of food on the basis of protecting its own interests. Establishing the operational channel of complaints, rights protection and counsel, encouraging the masses to report complaints, arouse the enthusiasm and initiative of the masses by rewarding the behavior of report complaints. In the country, the local government and the participation of the masses, eventually form the protection mechanism of three-dimensional structure of food safety, make the development of the rural self-produced food market into formal, and comprehensive protection of rural food.

\section{ACKNOWLEDGEMENT}

Thanks to The Provincial Training Programs of Innovation and Entrepreneurship for Undergraduates in 2015, entitled "The investigation of food security in the rural areas of western China" (Licensed No. 201510638062). And the Provincial Training Programs of Innovation and Entrepreneurship for Undergraduates in 2015 ,entitled "Studying on the road of enlarging power to towns--the first pilot towns in Nanchong" (Licensed No. 201510638059)

Thanks to my teacher who has been teaching for me, teaching me how to write the article and deal with the problem in the life, etc. Thank the students for my comment, and have been encouraging, make me better, more profound observation of the society. Thank of the friends from all walks of life for me, it is your support that make me finish this article, let me have more profound understanding to social 
security, food security.

\section{REFERENCES}

[1] General office of the national health and family planning commission of the food poisoning case in 2014. http://www.nhfpc.gov.cn/yjb/s3585/201402/f54f16a4156a460790caa3e 991c0abd 5.shtml). (In Chinese)

[2] HouYu, "status,gap and proposal of china's food safety," Food Research and Development, 2008, (1), pp56-59.(In Chinese)

[3] Ju Ronghui,Wang Xiaomei, "food Safety in building new socialist countryside," Chinese Agricultural Science Bulletin, 2009, 25(1), pp.272-275.(In Chinese)

[4] Ji Ping, "Rural food safety system in our country to build the legal dimension," Journal of Anhui Agricultural Sciences, 2012, 40(4), pp.2241-2243.(In Chinese)

[5] Liao Tianhu, "Talk about the our country rural food safety control system,” Rural Economy, 2013, 12(3), pp.95-99.(In Chinese)

[6] Ning De-huang, Jiao Qiang, "A Review on the research of Food Safety Issue in Rural Areas of China in Recent Years," Kun Ming University Science and Technology, 2014.,14(6),pp.24-29.(In Chinese)

[7] Sun Yanhua,Ying Ruiyao,"The empirical study of underdeveloped regions in rural food safety - based on the perspective of counterfeit and substandard food ," Rural Economy, 2007, 27(4), pp.93-95.(In Chinese)

[8] Wu Wei, "The rural circulation of food safety regulatory issues to explore - in hubei province as an example," Consumer Economics, 2009, 22(6), pp.40-42.(In Chinese)

[9] Wang Bei, "The Problems of Food Safety in Chinese Rural Area," Chinese Primary Health Care,2008, 22(12), pp.62-64. (In Chinese)

[10] Xiao Xuewen, 2013 .The mass line build food safety work pattern. http://www.scfda.gov.cn/CL2283/74421.html).

[11] Zhou Guangyao, "Rural food safety situation and countermeasures series," Journal of Central South University, 2006, 8(1), pp.15-17.(In Chinese) 